\title{
Microwave Induction Heating of Polymer-Modified Asphalt Materials for Self-Healing and Deicing
}

\author{
Mansour Fakhri ${ }^{1, *}$, Sajad Javadi ${ }^{1}$, Reza Sedghi ${ }^{2}$, Alireza Sassani ${ }^{3}$, Ali Arabzadeh ${ }^{4}([)$ \\ and Behnam Baveli Bahmai ${ }^{1}$ \\ 1 Department of Civil Engineering, K. N. Toosi University of Technology, Tehran 158754416, Iran; \\ sajadjavadi2012@gmail.com (S.J.); bavelibahmai@email.kntu.ac.ir (B.B.B.) \\ 2 Department of Civil Engineering, Tarbiat Modares University, Tehran 11114115, Iran; \\ rezasedghy@modares.ac.ir \\ 3 Institute for Transportation, Iowa State University, Ames, IA 50011, USA; asassani@iastate.edu \\ 4 Department of Civil, Construction, and Environmental Engineering, Iowa State University, \\ Ames, IA 50011, USA; arab@iastate.edu \\ * Correspondence: fakhri@kntu.ac.ir
}

Citation: Fakhri, M.; Javadi, S.;

Sedghi, R.; Sassani, A.; Arabzadeh, A.; Baveli Bahmai, B. Microwave Induction Heating of Polymer-Modified Asphalt Materials for Self-Healing and Deicing. Sustainability 2021, 13, 10129. https:// doi.org/10.3390/su131810129

Academic Editor: Rui Micaelo

Received: 16 July 2021

Accepted: 6 September 2021

Published: 10 September 2021

Publisher's Note: MDPI stays neutral with regard to jurisdictional claims in published maps and institutional affiliations.

Copyright: (c) 2021 by the authors. Licensee MDPI, Basel, Switzerland. This article is an open access article distributed under the terms and conditions of the Creative Commons Attribution (CC BY) license (https:// creativecommons.org/licenses/by/ $4.0 /)$.

\begin{abstract}
This study evaluates the influence of polymer-modification on the induction heating capability of asphalt mastic in a microwave field, and investigates how effectively this approach can be utilized for ice melting and self-healing purposes. To this end, different asphalt mastic mixtures with different polymer-modification and mixing procedures were tested under microwave field exposure for induction heating capability, ice-melting ability, and self-healing capacity. The mixtures were made through warm-mix and hot-mix procedures with four bituminous binders, including virgin (unmodified) asphalt and the same binder modified with three types of polymers. The results showed the effectiveness of microwave induction heating of asphalt mastic for both crack-healing and deicing purposes. The binder type was found to influence the ice melting and crack healing rates, such that using a warm-mix asphalt binder resulted in a more efficient heat generation and conduction than using a virgin asphalt binder. While polymer-modification undermined inductionheating, ice-melting, and self-healing performances, SBS-modified asphalt binders exhibited better performance than the other polymer-modified binders.
\end{abstract}

Keywords: self-healing; ice melting; warm mix asphalt mixture; hot mix asphalt mixture; microwave induction heating

\section{Introduction}

Asphalt binder can be modified with different materials such as polymers, jet grouting waste, steel slag, and recycled asphalt to achieve desired properties [1-5]. Asphalt binder is the residue of crude petroleum with properties depending on its source and refining process [6]. However, it is generally known as a viscoelastic material with a temperaturedependent dynamic behavior. Pavements made with asphalt materials undergo various distresses under the traffic-induced and environmental loads during their service life. The appearance and propagation of cracks are the primary and most critical forms of distress in asphalt pavements that reduce the serviceability of asphalt pavements, affecting the ride quality and safety. When properly designed, the asphalt pavement surface course must provide a reasonably long service life during which it maintains ride quality and skid resistance at satisfactory levels. With the current materials and practices, asphalt pavement cracking is inevitable, but the extent and severity of the cracks can be controlled through better materials and methods $[7,8]$. Modifying the asphalt binder is an approach to improving material properties and subsequently reducing cracking susceptibility. Asphalt materials have intrinsic self-healing properties that allow the closing of the existing cracks by heat. The self-healing properties can be enhanced through binder modification or the 
application of suitable additives. The effectiveness of crack healing also depends on the external stimulus, such as induction heating, used to raise the internal temperature and trigger the process [9].

Polymer-modified asphalt (PMA) is the conventional asphalt binder mixed with other polymers to achieve superior performance. Various polymers are used in the production of PMAs, while only a limited number of materials have shown adequate performance and received wide acceptance [10]. The polymers used for asphalt modification should possess enough stability to preserve their structure through the mixing process and establish a continuous polymer network with asphalt. One of the most commonly used polymers for asphalt modification is Styrene-Butadiene-Styrene (SBS). SBS forms strong styrene cross-links, leading to the formation of an elastomeric network. SBS has gained tremendous popularity in the asphalt research community. The existing literature is rich with studies investigating the compatibility of SBS with bitumen, optimum polymer concentrations, and the characteristics and performance of the SBS-modified bituminous mixtures [11-14].

High modulus bitumen (HMB) is a specific type of pure or modified bitumen used to reduce the thickness of the pavement layer [15]. The HMB used in high modulus asphalt concrete (HMAC) production may be made of high modulus binders or obtained by modifying conventional binders with high modulus additives [16]. Generally, there are three groups of the HMBs, including high-grade paving bitumen, HMB modified by asphaltene, and HMABs modified by polyolefin [17]. Despite the limited research studies about the elastic recovery of the HMB, Han Geng et al. observed that HMBs had higher complex modulus at $60^{\circ} \mathrm{C}$, but it had lower elastic recovery than a SBS-modified binder at $25^{\circ} \mathrm{C}$ [16]. Moreover, the elastic recovery of HMBs at $25^{\circ} \mathrm{C}$ was lower than the neat binder.

The self-healing of asphalt mixtures depends on the physical and chemical properties of their constituents. The short-term healing is primarily driven by the Van Der Waals forces and the intermolecular, hydrogenic interactions influencing the surface energy [18]. Previous studies have described various mechanisms that are possibly involved in the self-healing properties of asphalt mixtures. Notably, Castro and Sánchez referred to Sol-Gel processes in explaining the recovery of asphalt specimens during rest time. Self-healing occurs at high temperatures through the transformation of the asphalt binder from the Sol structure to the Gel structure, resulting in strength recovery [19,20]. Phillips [21] proposed three propagation models for bitumen healing: (1) closing resulted from the gathering of tensions and the flowing of bitumen, (2) wetting, in which the crack's sides are forced back together by surface energy, and (3) dispersion and randomization of asphaltene as the material attempts to regain its initial strength [21,22].

Strength recovery through self-healing is represented by the crack's free surface energy and internal dispersion of bitumen molecules [23]. According to Kringos et al.'s chemomechanical model [24], bitumen tends to undergo phase-separation under mechanical or environmental loads and develop enough energy at the interface of different phases to create micro-cracks which can propagate and merge into macro-cracks. The phases, however, may mix and rearrange into a more homogeneous state in response to increasing energy levels caused by temperature rise or mechanical stimuli. As a result, the bituminous mixture behaves as a single-phase material that recovers from micro-cracks, restoring its mechanical characteristics [24]. However, the self-healing or recovery of asphalt pavement in ambient temperature is low, and it is impossible to intervene in the traffic flow for a long time.

The mechanisms discussed in the literature, and mentioned above, show that the selfhealing of asphalt overwhelmingly depends on temperature. Previous research has identified temperature as the most influential factor in the self-healing of asphalt mixtures $[10,25]$. The asphalt self-healing rate (recovery level) increases when materials are subjected to high temperatures during rest time [26]. There is a consensus among researchers that the asphalt binders' healing capacity and rate are improved at higher temperatures, supporting the idea of using heat-based methods to induce self-healing in asphalt binders. Research has also found the fractional and chemical compositions of bitumen to affect self-healing 
performance. As a result of aging, the viscosity of bitumen increases, and its self-healing capability is decreased [27]. The extent of the influence of aging on asphalt binder's healing capacity varies by material and aging conditions [28].

Numerous studies have evaluated the self-healing properties of SBS-modified asphalt mixture or bituminous mastic. Quan Lv et al. [29] reported a negative impact of SBS (i.e., linear polymer) on the healing capability of bitumen in both dry and wet conditions. Contrarily, Daquan Sun et al. observed an improvement of healing rate and strength recovery with SBS modification of bituminous binders. In addition to better healing properties, SBS-modified bitumen likely shows less temperature sensitivity than the equivalent pure bitumen that can be ascribed to the absorption of the light components of bitumen by SBS particles [30]. Hence, the lower self-healing capability of SBS-modified bitumen reported by some studies, as mentioned above, can be related to the SBS-modified increase in viscosity and reduced temperature sensitivity caused by SBS modification. On the one hand, lower viscosity retards the flow of bitumen and, consequently, the crack healing. On the other hand, the SBS network fails to heal at the prevailing temperature due to its lower temperature sensitivity, and thus SBS particles act as fillers between the crack surfaces, reducing the healing capacity [31]. Qiu et al. [32] observed the same performance of SBS-modified bitumen when they compared the morphological characteristics of SBS-modified bitumen and pure bitumen. Their research demonstrated that SBS-modified bitumen had a lower crack healing speed than its non-modified (pure) equivalent.

The ice formation and snow accumulation on the surface of asphalt pavement during the winter can cause safety loss, congestion, and delay [33]. Deicing salts, the primary traditional ice/snow removal method besides mechanical removal, may cause environmental damage, primarily by contaminating the surface and ground waters. Deicing chemicals also can exacerbate freeze-thaw damage. For decades, research has explored alternative technologies to complement traditional ice and snow removal methods and improve the efficiency and effectiveness of winter maintenance operations. Microwave induction heating is one of the methods that has shown promising performance in ice and snow removal from pavement surfaces. Some desirable features that make this technique stand out include heating uniformity, flexibility, controllability, energy efficiency, and sustainability [7,34-36].

Conductive asphalt mixtures have served as the base technology for pavement deicing (self-heating or electrical heating) and self-healing asphalt mixtures. As an example, Sun et al. [37] reported on the deicing and snow melting applications of self-healing asphalt mixtures using thermal conductivity and microwave induction heating. In Sun et al.'s research, self-healing asphalt mixtures showed a desirable deicing performance under microwave heat induction, exhibiting a high deicing rate and efficiency [37]. In another study, Liu et al. investigated the self-healing capabilities of warm mix asphalt (WMA) and hot mix asphalt (HMA) using induction heating; this study reported comparable induction heating speeds, with both asphalt mixture types observing a slightly lower HI for WMA. While WMA showed a lower recovery level compared with HMA, the optimal healing temperature of WMA was lower due to its relatively higher-remaining — content of active constituents [38]. Fakhri et al. [39] studied the self-healing properties of WMA mixtures containing copper slag filler and steel fibers and observed that the presence of steel fibers increases the self-healing potential while copper slag filler improved heat dispersion.

There is a relatively rich literature about polymer-modified asphalt materials (i.e., asphalt concrete, asphalt mastic, and asphalt binder). However, most of the existing research on the polymer modification of asphalt mixtures focuses on the influence of different modifiers on the mechanical properties of asphalt mixtures. Thus far, the deicing and self-healing performances of this class of asphalt mixtures have not been evaluated simultaneously. In response to this gap in the existing literature, the research presented herein investigates the fracture characteristics, the self-healing potential, and the heating and deicing capabilities of polymer-modified bituminous mastic. The comparative analysis results of the influence of different polymers on the self-healing and induction-heating of polymer-modified asphalt provide grounds for future material development. Additionally, 
the outcomes of this study can be used to make more environmentally sustainable decisions about material selection, especially for pavement deicing purposes.

\section{Materials and Methods}

\subsection{Aggregate}

The aggregate type used to prepare asphalt mastic beams was crushed dolomite with a specific gravity of 2.65 (ASTM C127 was used to find the specific gravity of aggregate). Table 1 shows the aggregate gradation (based on the sieve series of ASTM E11) used in this research.

Table 1. Aggregate gradation.

\begin{tabular}{ccc}
\hline Sieve Number & Sieve Size $(\mathbf{m m})$ & Passing $\mathbf{( \% )}$ \\
\hline No. 4 & 4.720 & 100.0 \\
\hline No. 8 & 2.360 & 31.7 \\
\hline No. 16 & 1.180 & 20.8 \\
\hline No. 30 & 0.600 & 12.6 \\
\hline No. 50 & 0.300 & 8.3 \\
\hline No. 100 & 0.150 & 5.6 \\
\hline No. 200 & 0.075 & 0.0 \\
\hline
\end{tabular}

\subsection{Asphalt Binder}

The neat asphalt binder used in this research had a penetration grade of 60/70 and a specific gravity of 1.01. For making the WMA mastic samples, Sasobit ${ }^{\circledR}$ was added to the mixture at a rate of $1.5 \%$-by weight of neat binder-to reduce the viscosity and the mixing time. Three types of polymers: styrene-butadiene-styrene (SBS), RW Elast ${ }^{\circledR}$ (RWE), and RW Plast ${ }^{\circledR}$ (RWP) with the contents of, respectively, 4\%, 5\%, and 10\%-by weight of the neat binder, were used to obtain polymer-modified asphalt binders for making the polymer-modified mastics. The final mixtures were as follows:

- HMA mastics made with:

1- Neat (unmodified) bituminous binder;

2- Polymer-modified binder containing $4 \%$ SBS;

3- Polymer-modified binder containing 5\% RWE;

4- Polymer-modified binder containing $10 \%$ RWP.

- WMA mastics made with:

5- Neat (unmodified) bituminous binder and 1.5\% Sasobit;

6- Polymer-modified binder containing 4\% SBS and 1.5\% Sasobit;

7- Polymer-modified binder containing 5\% RWE and 1.5\% Sasobit;

8- Polymer-modified binder containing 10\% RWP and 1.5\% Sasobit.

Note that RWE is pellets of high-performance bitumen modified with SBS, so it is a form of SBS-based asphalt modification, while RWP is based on polyolefins. For binder polymer modification, a high-speed shear mixer was used to mix the asphalt binder and polymers at shear rates of 500 and $400 \mathrm{rpm}$ and a temperature of $170{ }^{\circ} \mathrm{C}$. The first shear rate was used during the addition of polymers, and the latter shear rate was used after the addition of the polymers. To develop polymer networks, the shearing-applied at the rate of $400 \mathrm{rpm}$-lasted for $120 \mathrm{~min}$. The properties of neat and polymer-modified asphalt binders are shown in Table 2. 
Table 2. The properties of neat and polymer-modified binders.

\begin{tabular}{|c|c|c|c|c|c|c|}
\hline \multirow[b]{2}{*}{ Property } & \multirow[b]{2}{*}{ Unit } & \multirow[b]{2}{*}{ Test Methods } & \multicolumn{4}{|c|}{ Results } \\
\hline & & & $\begin{array}{l}\text { Virgin Asphalt } \\
\text { Binder }\end{array}$ & $\begin{array}{l}\text { RWP-Modified } \\
\text { Binder }\end{array}$ & $\begin{array}{c}\text { RWE-Modified } \\
\text { Binder }\end{array}$ & $\begin{array}{l}\text { SBS-Modified } \\
\text { Binder }\end{array}$ \\
\hline $\begin{array}{l}\text { Penetration at } \\
25^{\circ} \mathrm{C}, 0.1 \mathrm{~mm}\end{array}$ & $0.1 \mathrm{~mm}$ & ASTM D5 & 65 & 10 & 20 & 50 \\
\hline Softening point ${ }^{\circ} \mathrm{C}$ & ${ }^{\circ} \mathrm{C}$ & ASTM D36 & 50.8 & 90 & 81 & 70 \\
\hline Ductility at $25^{\circ} \mathrm{C}$ & $\mathrm{Cm}$ & ASTM D113 & 100 & 20 & 40 & 64 \\
\hline $\begin{array}{c}\text { Kinematic viscosity } \\
\text { at } 135^{\circ} \mathrm{C}\end{array}$ & $\mathrm{mm}^{2} / \mathrm{s}$ & ASTM D 170 & 352 & 1027 & 1377 & 863 \\
\hline
\end{tabular}

\subsection{Specimen Preparation}

Figure 1 shows an example of asphalt mastic beam specimens prepared to characterize heat distribution, ice melting, and healing capabilities of the HMA and WMA mixtures used in this research. The HMA and WMA specimens were prepared in a Hobart mixer at $160{ }^{\circ} \mathrm{C}$ and $130{ }^{\circ} \mathrm{C}$ temperatures, respectively. The mixing continued until the aggregates were coated entirely with binders. After mixing, the asphalt mastics were hand-compacted in silicon molds. Three replicate specimens were made for each mixture. The specimens were allowed to cool in the molds, and then they were conditioned in a refrigerator set at $-20^{\circ} \mathrm{C}$ for $30 \mathrm{~min}$. Low-temperature conditioning was performed to facilitate demolding. A $2 \mathrm{~mm}$-deep notch was saw-cut in the middle of each beam after demolding to impose fracture at or near the midspan (see Figure 1).

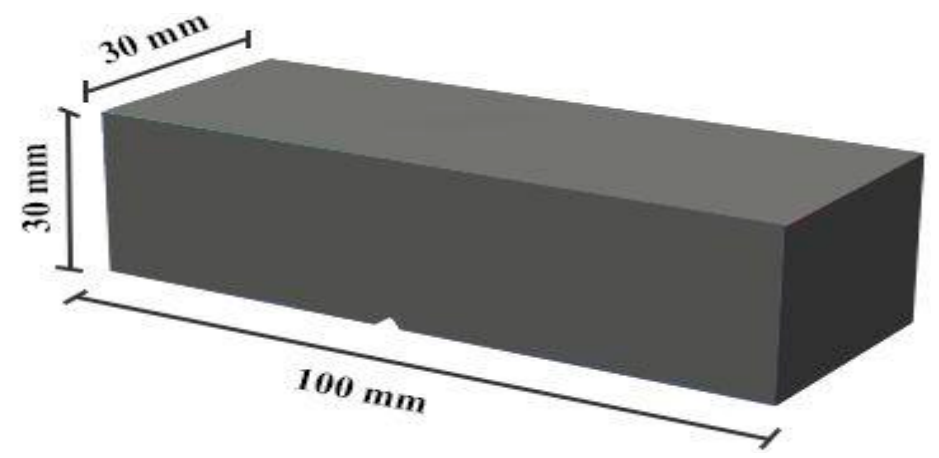

Figure 1. Schematic of the asphalt mastics specimens used in this study.

\subsection{Heat Distribution Characterization}

Figure 2 shows the test setup used for assessing the heat generation efficiency of the specimens. Heat distribution within the beam specimens was characterized using a microwave oven with an output power of $800 \mathrm{~W}$ and a frequency of $2.45 \mathrm{GHz}$ to generate/induce heat. Thermal images were taken with an infrared camera at $640 \times 480$ pixels resolution (see Figure 2). Infrared images were taken from the specimen's surface every $20 \mathrm{~s}$, and the images were used to obtain the average surface temperature. Note that this study was a laboratory investigation, while real-world applications will require more powerful induction heating systems capable of heating the pavement surface course at a larger scale. However, for laboratory test purposes, the system used in this study provides adequate power. Previous laboratory-scale studies have used microwave power equal to or lower than what was used in this study. For example, Fakhri et al. [39] used a microwave with the following characteristics: $800 \mathrm{~W}$ output power and frequency of $2.45 \mathrm{GHz}$ for heating the asphalt mixtures containing steel shaving and tire steel fibers or $\mathrm{Xu}$ et al. employed the microwave with $8300 \mathrm{~W}$ power and frequency of $123 \mathrm{kHz}$ for induction heating [40]. 


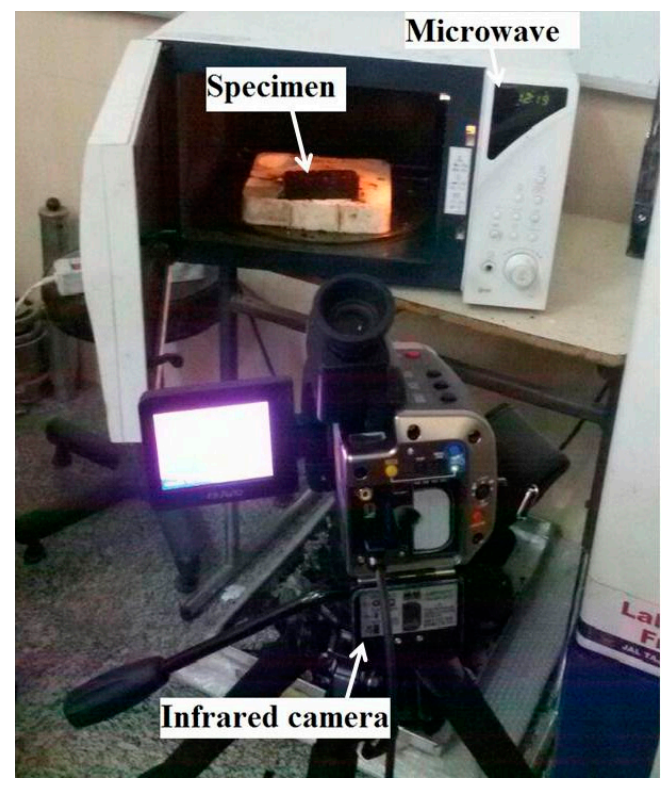

Figure 2. The test set up used for measuring the surface temperature on each specimen.

\subsection{Ice Melting Characterization}

The ice melting ability of the HMA and WMA mastic specimens under microwave induction heating was also characterized in this research. The main characteristics of interest in the ice melting experiment were the heat generation within the specimens, the surface heat distribution, and ice detachment from the surface. The specimens were heated through cyclic microwave stimulation as shown in Figure 3, each cycle comprising a heating duration of $20 \mathrm{~s}$ followed by a $10 \mathrm{~s}$ resting period. Cyclic heating was used for practical reasons; the door of the microwave device had to be opened for each measurement; designing the experiment based on cyclic heating helped avoid experiment interruption and the consequent errors. The measurements involved capturing an infrared image and manually applying an infinitesimal mechanical load to check if the ice layer is separable from the specimen; the whole process was completed in less than $10 \mathrm{~s}$. The final weight of the specimen after the separation of ice was also measured to calculate the ice melting speed (IMS). The IMS (or the rate of ice melting) for the separation of the ice layer was calculated based on the weight of the specimens before and after the experiment. Ice melting speed (IMS) was determined based on Equation (1):

$$
\mathrm{IMS}=\frac{\mathrm{m}_{1}-\mathrm{m}_{2}}{\mathrm{t}}
$$

where $\mathrm{m}_{1}$ (in $\mathrm{g}$ ) is the total weight of ice before heating; $\mathrm{m}_{2}$ (in $\mathrm{g}$ ) is the total weight of ice after heating, normalized by the weight-loss of ice during the same period within a microwave field with the same power, and $t(s)$ is heating duration. A more detailed description of this testing method can be found in [37].

\subsection{Characterization of Self-Healing through Measuring the Flexural Strength}

A three-point bending test was adopted after Liu [41] to examine the influence of polymer modification on the post-healing flexural strength of the HMA and WMA mastic specimens (see Figure 1). Figure 4 demonstrates the four-step of the testing procedure. In step one, the specimens were conditioned at $-20^{\circ} \mathrm{C}$. The second step was the three-point bending test that was run at the same temperature of $-20^{\circ} \mathrm{C}$ to prevent the deformation of the specimens when no load is applied. The load and deformation during the test was recorded continuously and used for calculating flexural strength $(\sigma f)$ according to Equation (2):

$$
\sigma f=\frac{3 p L}{2 d^{2}}
$$


where $\mathrm{P}$ (in $\mathrm{kN}$ ) is the applied peak load; $\mathrm{L}$ (in $\mathrm{mm}$ ) is the effective distance between the external supports with a value of less than $100 \mathrm{~mm}$ (see Figure 1); b (in $\mathrm{mm}$ ) is the specimen width with a value of $30 \mathrm{~mm}$ (see Figure 1); and $\mathrm{d}$ (in $\mathrm{mm}$ ) is the specimen height with a value of $30 \mathrm{~mm}$ (see Figure 1).

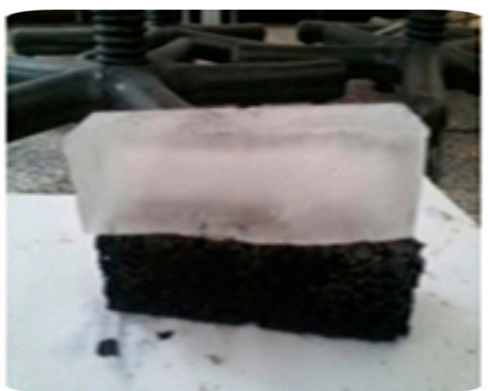

(a) Placing ice over the asphalt mastic specimen

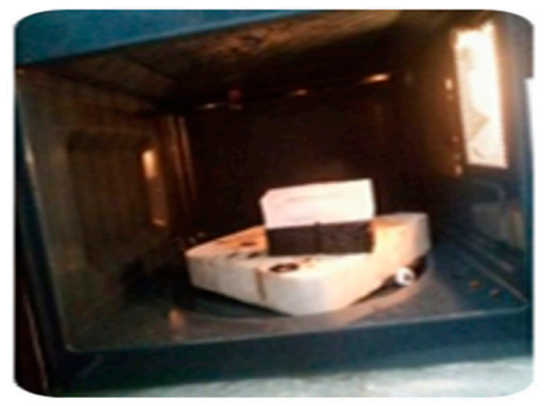

(b) Microwave induction-heating

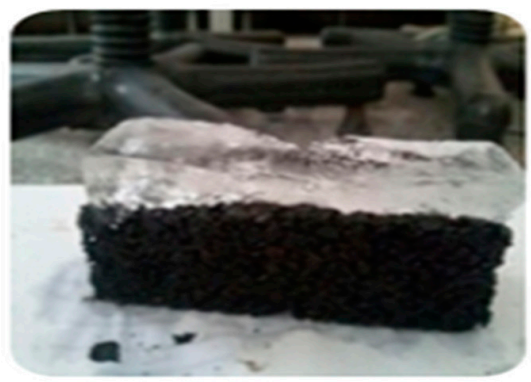

(c) Melting or detachment of ice after 120 seconds of induction-heating

Figure 3. Step-by-step demonstration of ice layer separation from an asphalt specimen.
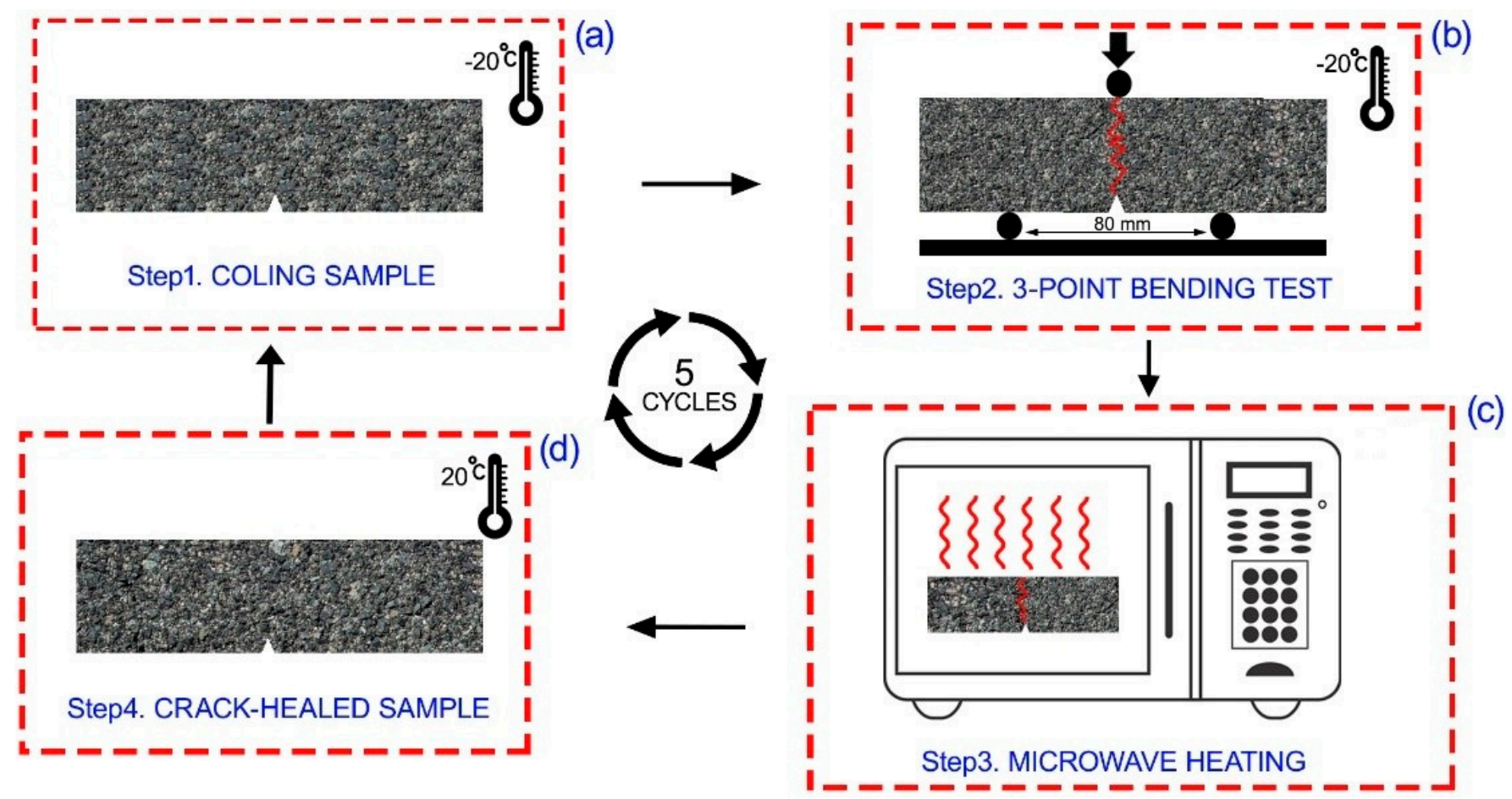

Figure 4. Schematic of crack-healing cycles with the aid of induction heating (a-d). 
In step three, the fractured (failed) specimens were healed through induction heating. The specimens were put under induction heating cycles at three different durations of 40,60, and $80 \mathrm{~s}$ to capture the influence of induction heating duration on the self-healing efficiency. Each heating cycle was followed by a freezing cycle in which the healed specimen was cooled down to $-20^{\circ} \mathrm{C}$ and kept at this temperature until reaching thermal equilibrium [42]. Then, the healed specimens were again subjected to flexural deformation until failure. The measurement of flexural strength before the heating and after the cooling cycles enabled the evaluation of the healing capacity under different induction heating durations (Figure 4). Five complete cycles were performed on each specimen at each heating duration.

\subsection{Characterization of Self-Healing through Measuring the Fracture Energy}

The recovery of fracture energy as a result of healing was also investigated. To this end, the fracture energy indices were determined before and after applying each heatingcooling cycle using the three-point bending beam test results. In this way, the cracking behavior could be quantified, and a fracture energy index (EI), representing the fracture energy recovery, could be proposed for each asphalt mastic type as given by Equation (3). Previously, Pan et al. [7] used a similar method to investigate the effect of different additives on the self-healing of asphalt mixtures containing sunflower oil, aromatic oil, bitumen emulsion, and maltene-based emulsions in terms of fracture energy recovery.

$$
\mathrm{EI}[\%]=\frac{\mathrm{E}_{\mathrm{h}}}{\mathrm{E}_{\mathrm{i}}} \times 100
$$

where, $E_{h}$ and $E_{i}$ are the fracture energies $\left(\frac{\mathrm{J}}{\mathrm{m}^{2}}\right)$ before and after the heating cycle, respectively, obtained from Equation (4). According to Equation (4), the fracture energy is defined as the work required to break a specimen through its ligament area [43]:

$$
\mathrm{E}=\frac{\mathrm{W}_{\mathrm{f}}}{\mathrm{A}_{\text {lig }}}
$$

where the superscripts $i$ and $h$ represent the fracture energies (in $\frac{\mathrm{J}}{\mathrm{m}^{2}}$ ) before (intact stage) and after healing of the specimens, respectively. $\mathrm{A}_{\text {lig }}$ is the ligament area $\left(\right.$ in $\left.\left(\mathrm{m}^{2}\right)\right)$ obtained from Equation (5), and $\mathrm{W}_{\mathrm{f}}$ is the work of fracture (in (J)) obtained from Equation (6).

$$
\mathrm{A}_{\text {lig }}=(\mathrm{d}-\mathrm{a}) \mathrm{t}
$$

where $t, a$, and $d$ are the width, notch length, and thickness of the specimen, respectively.

$$
\mathrm{W}_{\mathrm{f}}=\sum_{\mathrm{i}}^{\mathrm{n}} \frac{1}{2}\left(\mathrm{~F}_{\mathrm{i}+1}+\mathrm{F}_{\mathrm{i}}\right)\left(\mathrm{d}_{\mathrm{i}+1}-\mathrm{d}_{\mathrm{i}}\right)
$$

where $F_{i}$ and $F_{i+1}$ are the applied loads at loading steps of $i$ and $i+1$, respectively; and $d_{i}$ and $d_{i+1}$ are displacements at times of $i$ and $i+1$, respectively.

\subsection{Deicing Performance in Terms of Heat Distribution on the Specimens' Surfaces}

Induction heating, using a coil, requires incorporating electrically conductive additives into asphalt materials to enable heat generation through Eddy currents. Coil-enabled induction heating involves induction of electric current and subsequent conversion of the electrical energy into heat through electrical resistance. Microwave-enabled induction heating involves directly converting electromagnetic energy into heat energy through interactions between the material and the electromagnetic field at a molecular/atomic scale. During microwave heating, electromagnetic energy converts to heat due to the change in the direction of bipolar molecules, and the heat partially migrates to the surface of materials (based on Salih et al. [44]). The extent and nature of a material's response to electromagnetic field depend on its constitutive parameters, magnetic permeability $(\mu)$ and electrical permittivity $(\varepsilon)$, and the magnetic field's characteristics (frequency and 
variation). However, the material-field interactions occur throughout the material's volume allowing volumetric heating $[45,46]$. Microwave absorption by the material is governed by dielectric properties that are defined by dielectric constant $\left(\varepsilon^{\prime}\right)$, dielectric loss factor $\left(\varepsilon^{\prime \prime}\right)$, dissipation factor or loss tangent $(\tan \delta)$, the most important one being dielectric loss factor which relates to how much microwave energy is converted into heat. Microwave power absorption (Watt $/ \mathrm{cm}^{3}$ ) can be represented by the following Equations (7) and (8) [47]:

$$
\begin{gathered}
\mathrm{P}=55.6 \times 10^{-14} \mathrm{f} \varepsilon^{\prime} \tan \delta \mathrm{E}_{0}^{2} \\
\mathrm{P}=55.6 \times 10^{-14} \mathrm{f} \varepsilon^{\prime \prime} \mathrm{E}_{0}^{2}
\end{gathered}
$$

where $\mathrm{f}$ is the frequency $(\mathrm{Hz})$, and $\mathrm{E}_{0}$ is the field strength in Volt $/ \mathrm{cm}$. Additionally, microwave-induced temperature change in a given material without considering the effects of heat conduction and convection can be approximated by Equation (9) [47]:

$$
\text { Temperature rise rate }\left[\frac{{ }^{\circ} \mathrm{C}}{\mathrm{s}}\right]=\frac{13.288 \times 10^{-14} \mathrm{E}_{0}^{2} \varepsilon^{\prime} \tan \delta}{\mathrm{c} \rho}
$$

where $\mathrm{c}$ is the material's specific heat $\left(\mathrm{cal} / \mathrm{g} \cdot{ }^{\circ} \mathrm{C}\right)$, and $\rho$ is the material's density $\left(\mathrm{gm} / \mathrm{cm}^{3}\right)$. The equation shows that the temperature rise has a reverse relationship with the material's density and specific heat. Nevertheless, microwave absorption increases with density, especially in asphalt materials, due to the increase in the concentration of wave-absorbing matter with density. On the other hand, it is inferred from the properties of materials and the findings of previous studies that the addition of polymers to asphalt binder is assumed to have a negligible effect on dielectric characteristics $[48,49]$. Therefore, the heating performance of asphalt material follows the balance between the influence of material density on microwave absorption and the higher energy requirement for raising the temperature of higher-density materials. Additionally, the material density, primarily defined by the degree of compaction, influences the heat generation uniformity, which has a significant role in the ice melting performance. These phenomena will be further discussed based on the surface heating and ice melting experiments' results. Note that microwave heating is a complex phenomenon depending on many electromagnetic-wave and material factors; therefore, this study attempts to explain the observed heating behaviors of the studied materials based on the rheological and physical characteristics. To this end, both measured characteristics and the existing literature were utilized to investigate the likely mechanisms behind the observations.

Contrary to microwave-enabled induction heating, heat generation in the currentbased heating methods, including inductive (Eddy current) and resistive Joule heating, follows the current path through the material and does not involve volumetric heating. In composite and heterogeneous materials, such as asphalt and Portland cement concretes, electrical conductivity varies throughout the material's volume, and there are even nonconductive zones within the material. The electric current flows through heterogeneous, polymer-based, or cementitious electrically conductive composites in separate paths with varying current magnitudes creating different Joule heating zones [50-52]. Considering that part of the microwave-induced heat is conducted to the material's surface, and this amount of heat is proportional to the total amount of heat generated, it is possible to evaluate the heating efficiency from the surface temperature using an infrared imaging system.

\section{Results and Discussion}

\subsection{Evaluation of Heat Distribution on the Specimens' Surfaces}

Figure 5 presents the average surface temperature for all the asphalt mastic specimens under different durations of microwave induction heating. As Figure 5 shows, the surface temperature increases with induction duration. The volumetric heating mechanisms mentioned above enable heating the materials in a faster and more uniform fashion, obvi- 
ating the need for the incorporation of electrically conductive additives [53]. Figure 5 also indicates that for all binder types, the WMA specimens reached higher surface temperature than HMA specimens made with the same binder type. WMA provides a superior workability and compactability [54], and consequently a higher density; hence, the volumetric induction heating is more effective in the case of WMA specimens and the heat transfer to the surface occurs through a more continuous, uniform medium. Additionally, WMA binder tends to give a lower viscosity than HMA equivalent, particularly due to the reduction in production aging and the presence of Sasobit ${ }^{\circledR}$ modifier $[55,56]$; as a result, the asphalt binder softens more during the heating process, reducing the porosity and improving both microwave energy absorption capacity and heat conductivity.

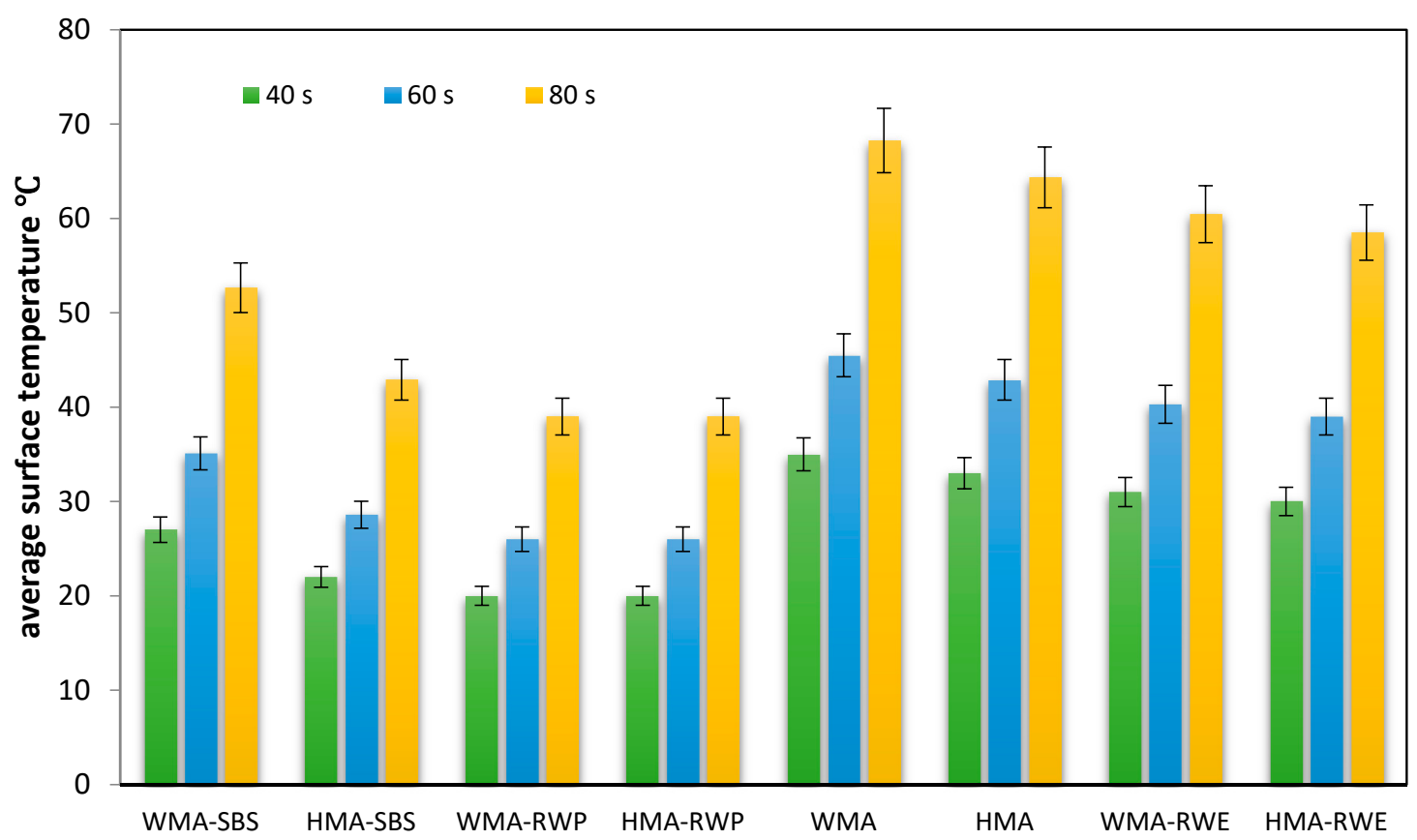

Figure 5. The temperature of specimens.

The WMA specimens made with virgin binder showed the highest surface temperature at all three durations. The test results indicated that polymer modification reduced the heat generation capacity of the specimens, such that the specimens made with virgin binder showed a better heating performance than their polymer-modified counterparts at all durations. RWE-modified specimens reached a higher average surface temperature than the other polymer-modified samples in the surface heating test. SBS- and RWP-modified specimens ranked second and third among the polymer-modified samples concerning average surface temperature. The WMA-RWP and HMA-RWP specimens showed an identical performance, unlike SBS- and RWE-modified ones, in which WMA samples performed better. The results of the ice melting test, presented in the next section, will shed more light on the induction heating performance of the specimens.

\subsection{Evaluation of Ice-Melting Efficiency under Microwave Heating}

Snowplowing equipment can effectively remove snow, but they cannot efficiently detach the ice from pavement surfaces. This shortcoming of current snow removal methods and the safety risks of icy roads have motivated researchers to seek more effective methods for removing ice from pavements. The most researched methods to fight ice formation and accumulation on pavement surfaces involve ice-phobic coatings and heated pavement systems [56,57]. Thus far, no alternative ice/snow removal method has gained wide acceptance to be even distantly comparable to the traditional methods. The alternative solutions proposed so far have not shown a persuasive combination of effectiveness, economic viability, and practical feasibility, while, on the other hand, the prevailing circumstances 
in different places are too variable to be addressed by a single method. Therefore, wide acceptance of a single alternative method is unlikely to happen in the foreseeable future. It is thus imperative to provide more alternative methods and to improve the existing ones so that a comprehensive inventory of solutions is available to address the issue of frozen pavement under varying circumstances. Induction heating can provide another alternative for the removal of ice from the surface of pavements.

Most research concerning induction heating application for pavement deicing has used electrically conductive materials; for instance, in recent research, Liu et al. [58] investigated the ice melting capability of steel shaving-incorporated asphalt mixtures through induction heating. In that study, they completely melted ice on the surface of their electrically conductive asphalt mixture specimens. Unlike the previous studies, the research presented herein aimed to use non-conductive pavement materials, i.e., virgin and polymer-modified asphalt mastics, and only separate the ice layer from the surface rather than entirely melting it. In real-world applications, it is more practical to detach the ice layer from the pavement surface using an induction heating element passing on the pavement surface instead of melting the ice in its entirety. In this way, there would not be a need to impart electrical conductivity to the pavement surface course and consume a tremendous amount of energy to melt the ice through induction heating.

Detaching the ice would be enough to apply an infinitesimal mechanical load using snowplowing equipment to wipe the ice off the surface. Therefore, the method introduced in this research targets the ice-surface adhesion and attempts to destroy the physical bond between the ice and the pavement surface using the principles of induction heating and heat transfer. In induction heating, the wave energy from the electromagnetic wave (microwave spectrum here) is converted into heat as a result of the wave-material interaction; then, the generated heat is transferred to the surface, which is colder than the material's volume, due to temperature gradient [59-61]. Figure 6 shows the thermographic images of the ice melting test on WMA-SBS specimens. As seen in Figure 6, the ice layer on the specimen's top surface melted in the $120 \mathrm{~s}$ test duration. According to Sun et al. [37], the duration of induction heating directly relates to the rate at which the physical bond at the ice-pavement interface is weekend. Therefore, the ice melting speed (IMS) was used to characterize the quality of ice separation from the specimen surfaces. The ice melting process for one of the specimens with time is shown in Figure 6.

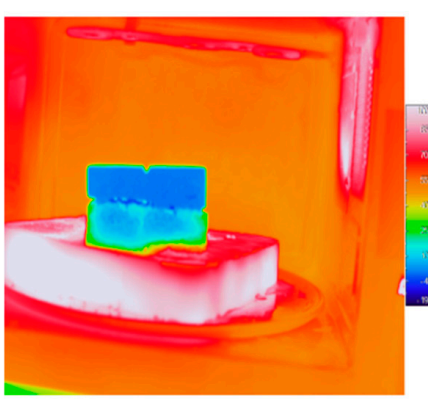

20 Seconds

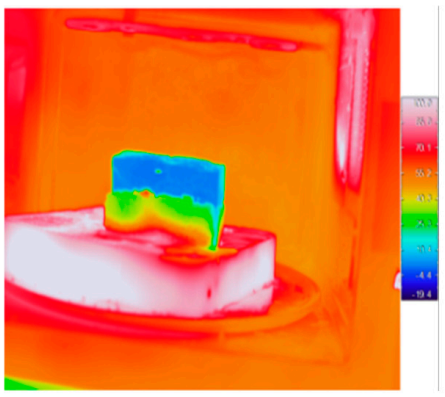

80 Seconds

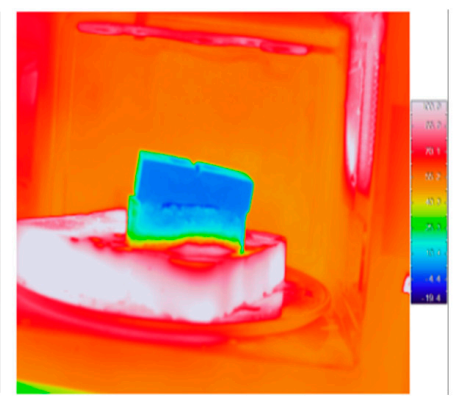

40 Seconds

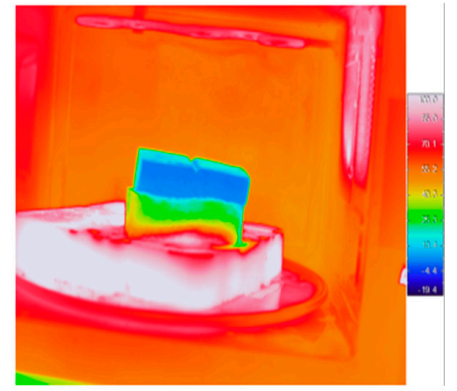

100 Seconds

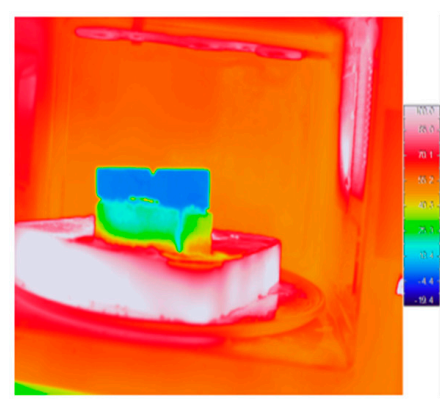

60 Seconds

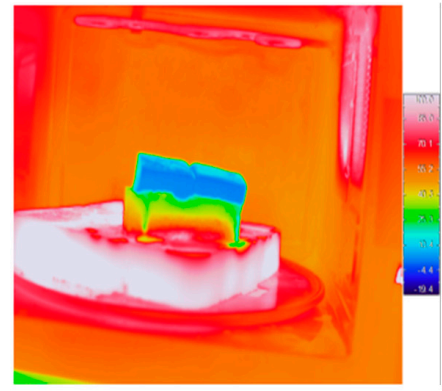

120 Seconds

Figure 6. The infrared images captured during the ice melting for a specimen made of WMA-SBS. 
Figure 7 presents the IMS mean values for the specimens exposed to induction heating. As seen in Figure 7, IMS considerably varied with the asphalt binder type used in the asphalt mastic specimens. Similar to the surface heating performance, the virgin samples gave a higher IMS than the polymer-modified, and the WMA specimens showed a higher IMS than their HMA counterparts (HMA specimens containing the same binder). Some factors behind the better heating performance of WMA samples were discussed in the previous section. It is worth mentioning that one of the main disadvantages of microwave heating is the non-uniformity of volumetric heat generation caused by the irregularities in the electromagnetic field and the non-homogeneity of material properties. Material properties, such as dielectric properties, polarity, material state, atomic/molecular weights, and density, vary throughout the volume of heterogeneous material, such that a considerable fraction of material can be microwave-transparent [62]. Lower viscosity and softening point of the virgin binders, WMA, and SBS-modified samples are positive forces to enhance their uniformity and density, primarily upon induction heating when the binder flows through the microwave-transparent voids and the aggregate-binder interfaces.

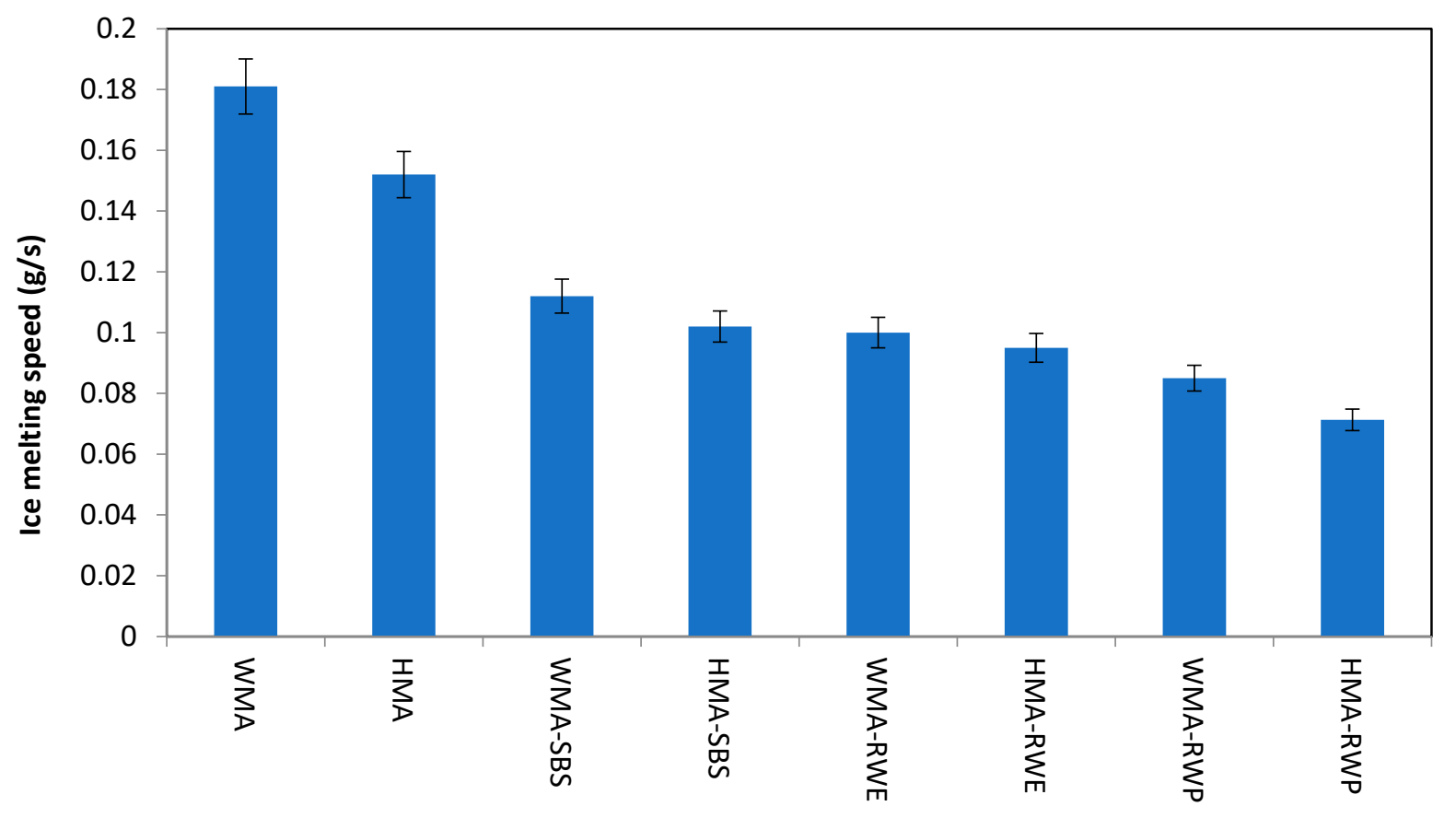

Figure 7. The mean of IMS of specimens.

RWE specimens showed a better surface heating performance than SBS specimens, while the SBS and RWP performed better than RWE in the ice melting test. It was observed that the IMS of WMA-SBS was $26.1 \%$ and $32.89 \%$ greater than WMA-RWP and WMA-RWE, respectively. Virgin binders have lower viscosity and softening points than the polymermodified binders, giving them more appropriate compatibility and higher density and uniformity, while being considerably more susceptible to heat-induced softening under microwave heating. Therefore, the virgin binders perform better in void filling, and, consequently, the specimens made with virgin binders achieve a more uniform volumetric heating and higher heat conductivity. On the other hand, among the polymer-modified binders, the SBS-modified binder has the lowest viscosity and softening point, making it come second after the virgin binders in ice melting performance.

An interesting observation was that the RWP-modified specimens that had the lowest surface temperature rise in the heating test performed better than the RWE-modified specimens, which had shown the highest surface temperature rise. Let us remember that the RWP-modified binder has a lower viscosity but higher softening point than the RWEmodified binder. On the other hand, the uniformity of temperature rise from $40 \mathrm{~s}$ to $60 \mathrm{~s}$ 
and from $60 \mathrm{~s}$ to $80 \mathrm{~s}$ in the surface heating test among all types of specimens implies that the differences of the binders in terms of heat-induced flow and void filling are not a significant factor of performance. In other words, the characteristics of the specimens before exposure to microwave field, i.e., the viscosity of binder, density, homogeneity, and molecular structure, are more significant factors in microwave-enabled induction heating performance.

Therefore, the better performance of RWP-modified specimens than the RWE-modified ones can be attributed to the higher initial density that enables a more uniform volumetric heating, better heat conduction, more uniform ice-asphalt interface, and, finally, a more effective transfer of heat to the ice layer. The average surface temperature on RWE-modified specimens was higher than both SBS-modified and RWP-modified specimens, possibly due to the effect of selective heating, which created over-heated zones on the specimens' surfaces. In comparison, the SBS- and RWP-modified specimens enabled a more uniform volumetric heating and a denser interface of ice and asphalt mastic.

\subsection{Self-Healing Potential (Three Points Bending Test)}

As, in this research, the crack closure was observed after completing the healing cycles, it was decided to evaluate strength recovery for all the mastic specimens made of WMA and HMA. Figure 8 presents the initial flexural strength values calculated for all the specimens after the failure in the first cycle. As seen in this Figure 8, all of the HMA mastic specimens have higher initial strength than the WMA mastic specimens. In addition, the initial flexural strength of HMA-SBS specimens was, on average, 58.73\%, 25.58\%, and 9.48\% greater than the HMA, HMA-RWP, and HMA-RWE specimens, respectively. As shown in Figure 8, the RWP-modified asphalt binder gave mastic specimens with lower flexural strength than the mastics made with the other polymer-modified asphalt binders. For example, HMA-RWP is $20.7 \%$ lower in terms of flexural strength than HMA-SBS, respectively. In addition to calculating the initial flexural strength values, the healing index-i.e., the flexural strength gained/recovered after exposure to microwave radiation for different durations of 40,60, and $80 \mathrm{~s}$-was calculated (see Figures 9-11) for all the specimens.

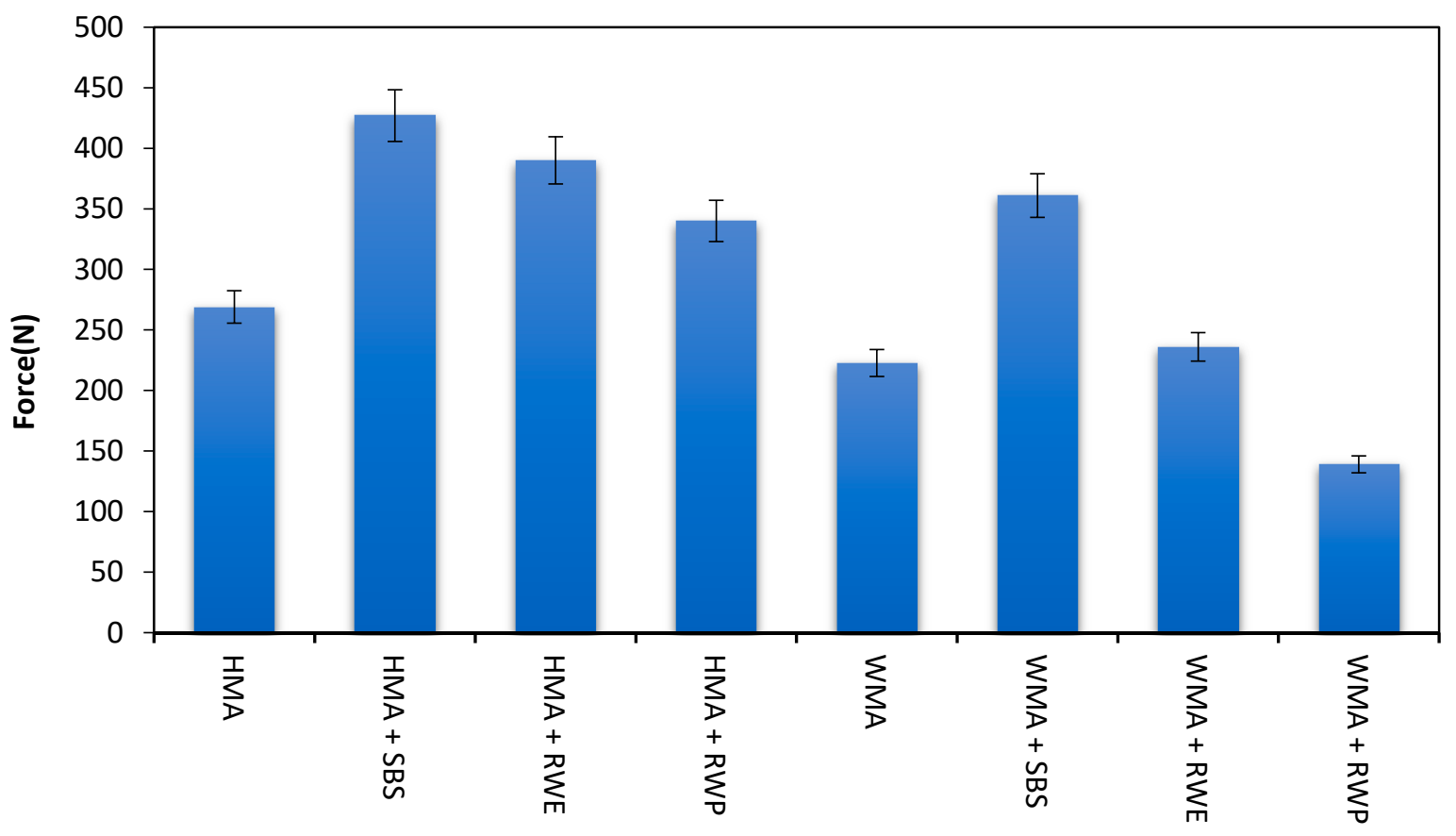

Figure 8. The mean of applied loads to each specimen after failure. 


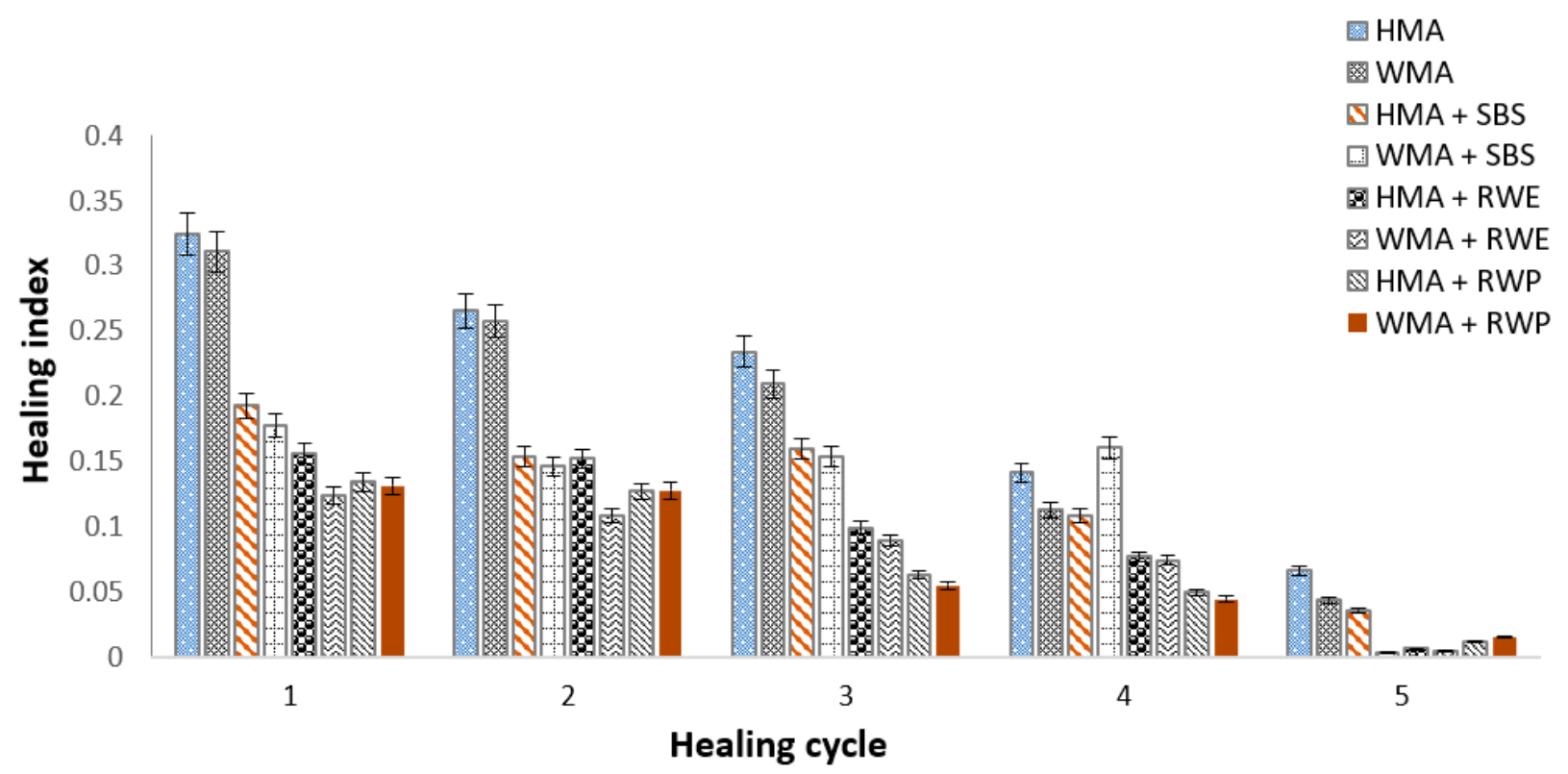

Figure 9. The healing index (HI) after $40 \mathrm{~s}$ induction heating.

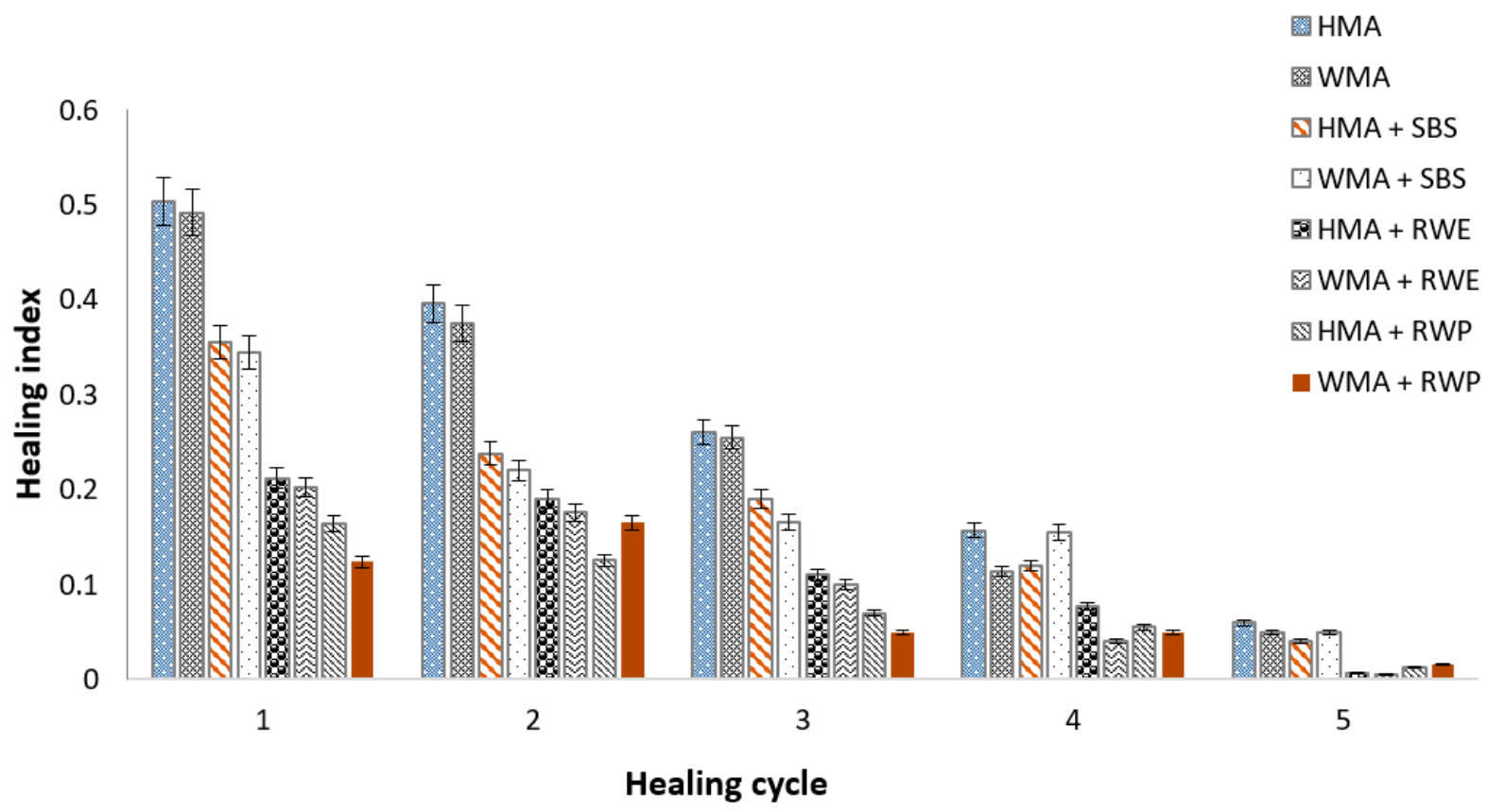

Figure 10. The healing index (HI) after $60 \mathrm{~s}$ induction heating.

Figure 9 shows the flexural strength recovery for all the specimens under different induction heating durations. The results indicated that with the increase in healing/fracture cycles, less strength is recovered. This finding agrees with Dai et al. [63], noting that, regardless of healing temperature, the healing index of specimens subjected to the threepoint bending beam test decreases with the increase in healing/fracture cycles. The results for the recovered flexural strength of the specimen exposed to $40 \mathrm{~s}$ of induction heating are provided in Figure 9. Based on the results presented in Figure 9, it was indicated that $40 \mathrm{~s}$ induction heating would be beneficial, such that the mean value of $\mathrm{HI}$ for specimens after $40 \mathrm{~s}$ heating was about $13.3 \%$. This means the closing of micro-cracks within the asphalt mastic specimens. Additionally, Figure 10 shows that specimens made of neat binder (HMA samples) have a higher capability of flexural strength recovery due to their lower softening point and viscosity. Furthermore, it was revealed that the HI value of the HMA-SBS specimen was $2 \%$ and $3.2 \%$ greater than HMA-RWE and HMA-RWP, respectively. 


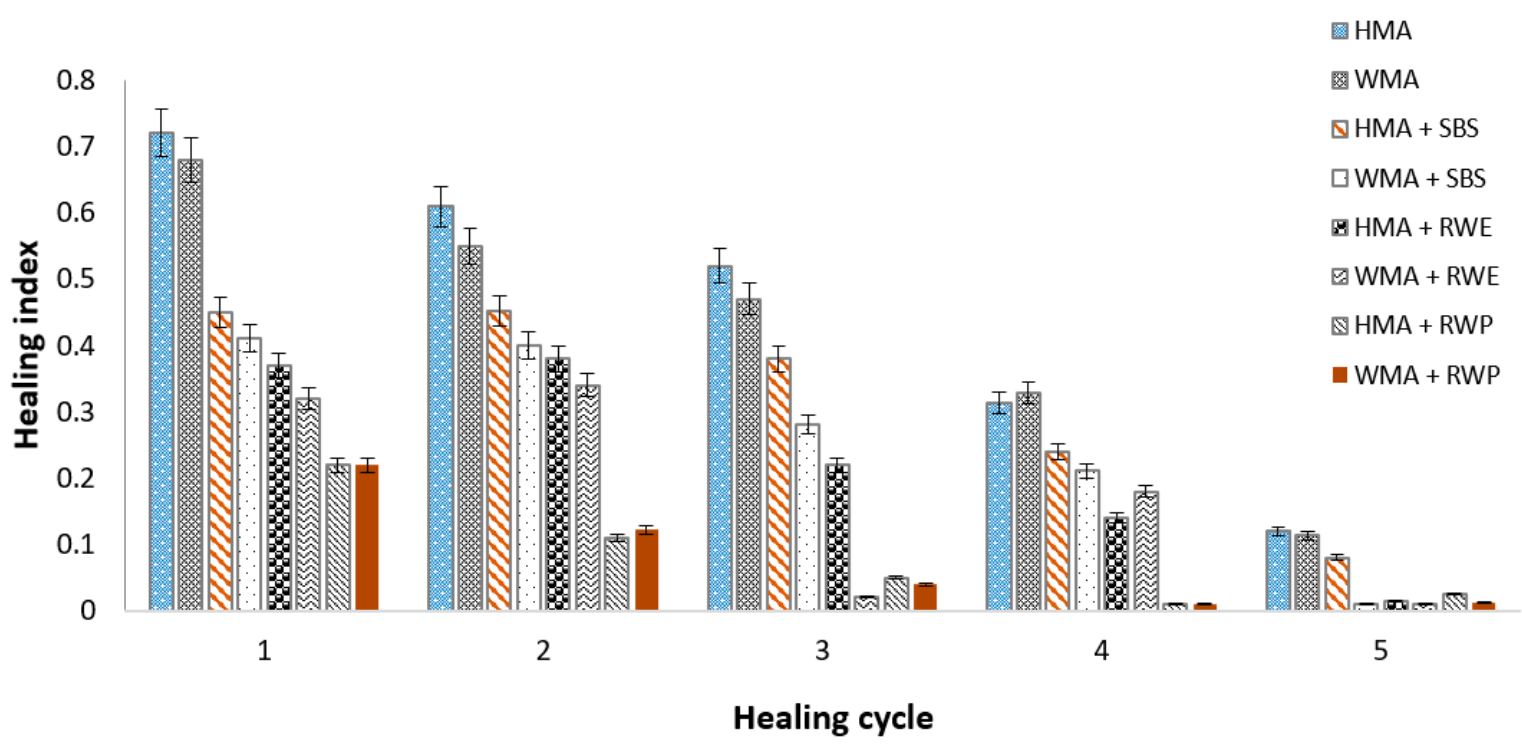

Figure 11. The healing index (HI) after $80 \mathrm{~s}$ induction heating.

The mean HI of specimens subjected to $60 \mathrm{~s}$ heating duration was 0.32 (see Figure 10), resulting in the closure of more cracks within the asphalt mastic specimens. According to Figure 10, the HMA specimens have higher HI values, i.e., recovered flexural strengths. Additionally, it was found that the HI values calculated for HMA-SBS specimens were about $32.45 \%$ and $68.98 \%$ greater than those calculated for HMA-RWE and HMA-RWP specimens, respectively. The further increase in temperature, i.e., an increase in heating duration from 60 to $80 \mathrm{~s}$, leads to an additional increase in the HI values. The mean value of $\mathrm{HI}$ for the $80 \mathrm{~s}$ heating duration was also calculated. This calculation resulted in a value $56.36 \%$ higher than that calculated for the specimens exposed to the heating duration of $60 \mathrm{~s}$. Such an increase proves the significant influence of heating duration on the crack healing capacity of the asphalt mastic specimens. The reason behind this behavior can be explained as follows: asphalt binder cannot flow easily within the formed cracks, and specimens consequently be repaired appropriately.

The closing of micro and macro cracks is swifter at higher temperatures and results in faster healing. Additionally, the increase in temperature leads to the closing of the macrocracks large enough to be closed at a low temperature. When two surfaces of cracks reach and come into contact with one another, the transition of asphalt binder molecules from one surface to another, and the rearrangement of asphaltene structures, leads to the recovery of strength, and high temperature helps magnify these parameters. Finally, the recovery of the strength of cracked asphalt at the high temperature would be noticeable. The utilization of asphalt recovery, based on the induction heating of asphalt pavement, leads to reduced fuel consumption or other unrecoverable resources, and it would meditate the asphalt production's negative environmental impacts.

\subsection{Fracture Energy Test}

Figure 12 shows that the presence of the elastoplastic polymer, i.e., the SBS, in both types of mixtures (WMA and HMA) resulted in the highest fracture energy values. The figure provides fracture energy ratios (EIs) obtained for all the specimens calculated after each healing cycle. This finding agrees with previous studies, particularly Pirmohammad and Ayatollahi [64] and Bazzaz et al. [65-67]. The former investigated the influence of binder modification with SBS on improving HMA and WMA performance. Bazzaz et al. [65-67] used linear viscoelastic (LVE) and nonlinear viscoelastic (NVE) responses to evaluate the creep-recovery characteristics of asphalt mixture in terms of strain recovery; they concluded that polymer-modified bitumen exhibited a lower strain recovery (due to higher elastic modulus) compared with the unmodified. 


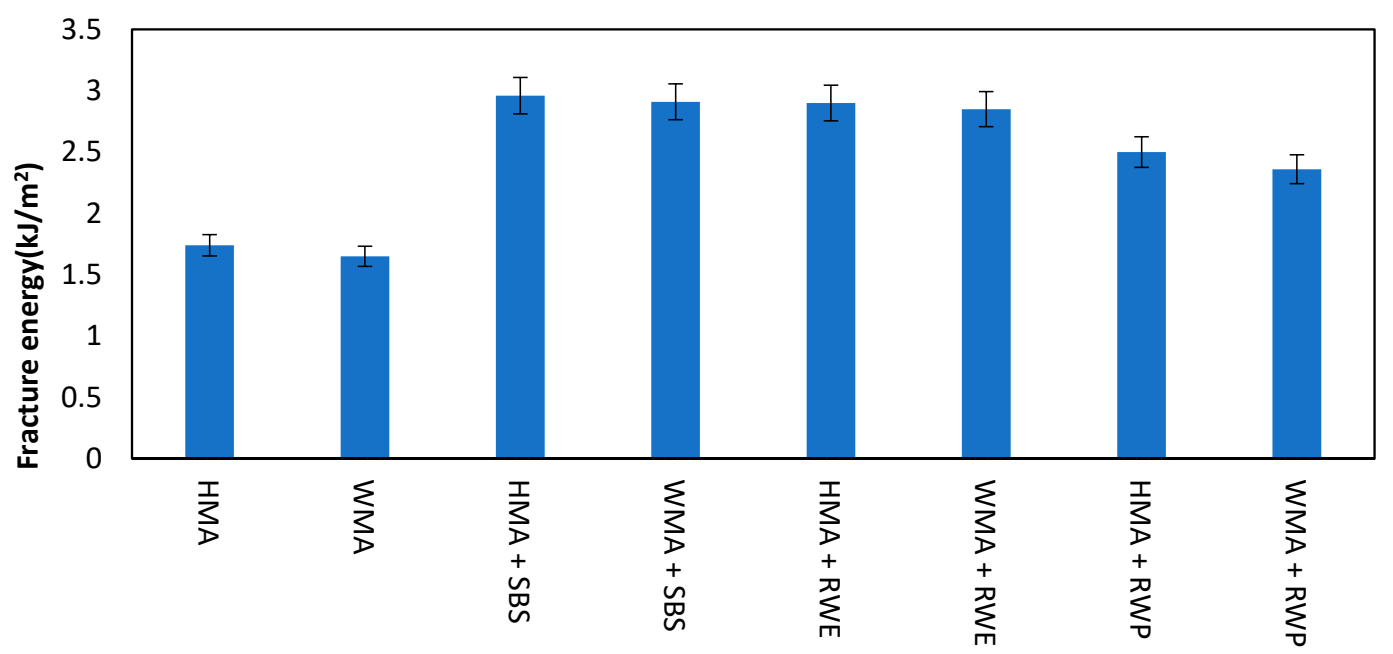

Figure 12. The initial fracture energy of asphalt mixture specimens.

According to the results shown in Figure 13, the EI indices or fracture energies decrease by increasing cycles. The healing of asphalt materials, or crack closure, depends on the asphalt binder cohesion and adhesion recovery. When the asphalt binder temperature increases to a level at which this material acts as a Newtonian fluid, the result would be: (1) the closure of cracks within the asphalt binder (or the enhancement of cohesion), and (2) the increase in bond at the asphalt binder-aggregate interface (or the enhancement of adhesion). Therefore, extending the healing duration increases the EI value. Generally, the EI values calculated for specimens made of the neat binder are greater than those made with polymer-modified binders. In addition, the use of WMA technology used for the modification of binders did not result in a significant influence on changing the EI values.

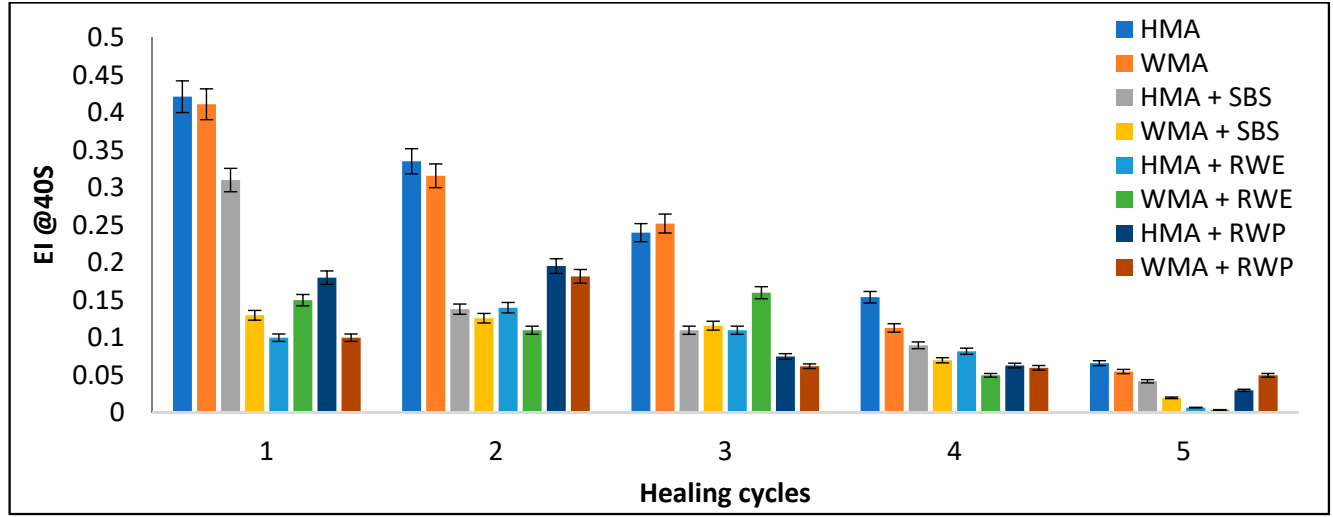

(a)

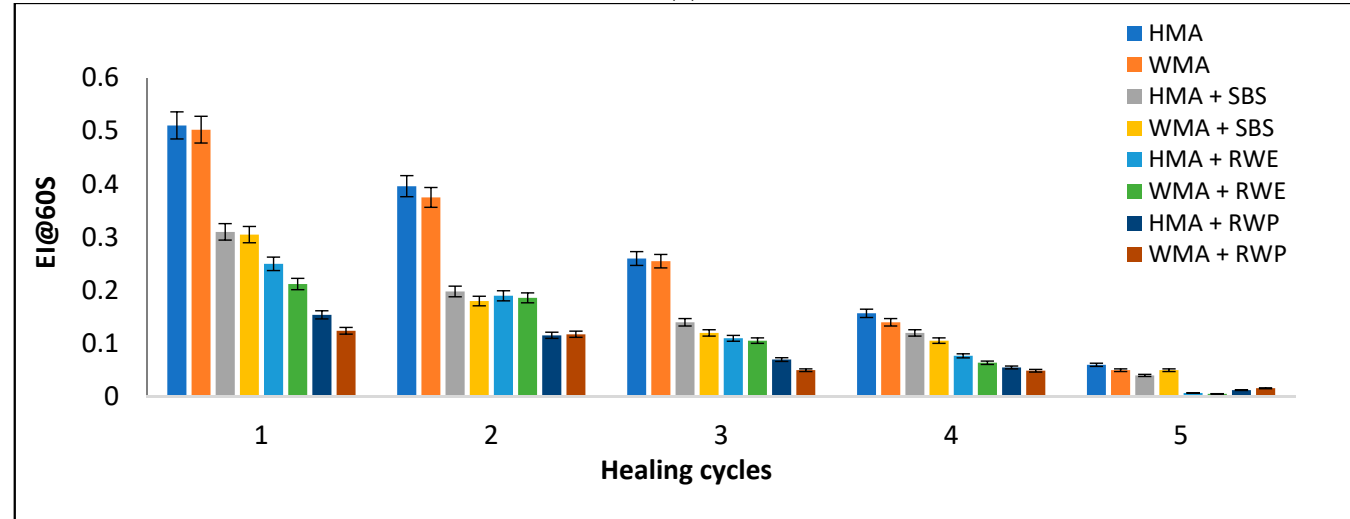

(b)

Figure 13. Cont. 


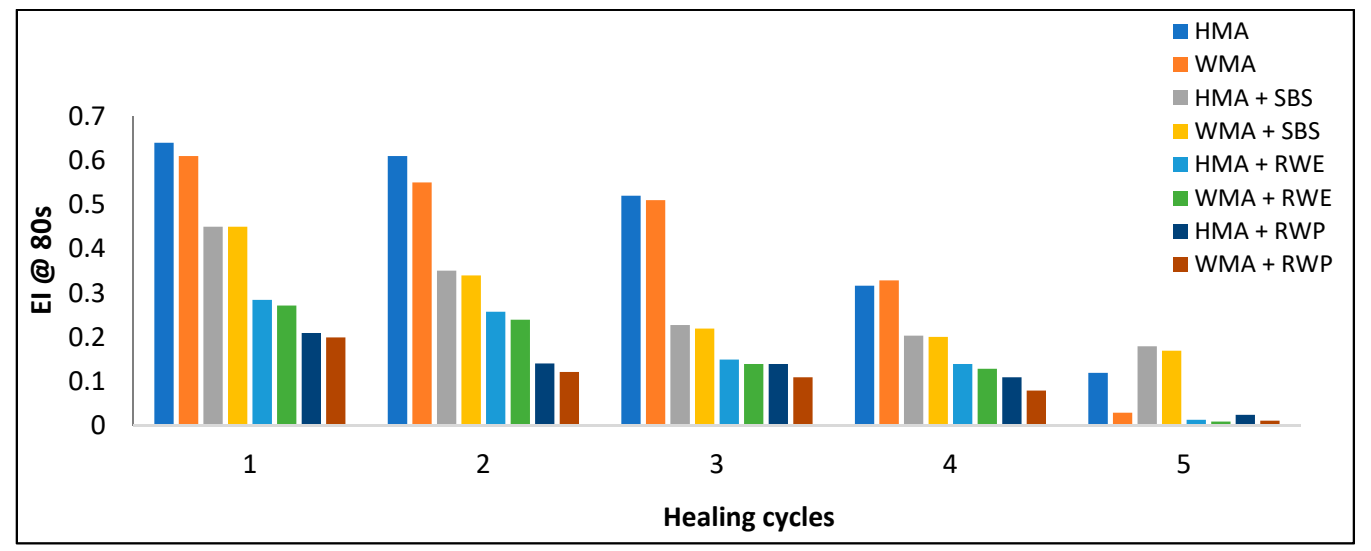

(c)

Figure 13. The ratio of fracture energy in five cycles of fracture-healing after (a) $40 \mathrm{~s}$ heating, (b) $60 \mathrm{~s}$ heating, and (c) $80 \mathrm{~s}$ heating.

\section{Conclusions}

This research aimed to investigate the effect of polymer modification on the inductionheating capability of hot and warm mix asphalt and how it relates to self-healing and ice melting performances. The polymers used for modifying the virgin bituminous binder were styrene-butadiene-styrene (SBS), RW Elast ${ }^{\circledR}\left(\right.$ RWE), and RW Plast ${ }^{\circledR}$ (RWP) in dosages of $4 \%, 5 \%$, and $10 \%$ by weight of the virgin binder, respectively. The main findings of the study can be summarized as follows:

- Polymer-modified asphalt binder, with low softening point and viscosity, decreased the ice melting speed and self-healing rate of bituminous mastic. Warm mix asphalt samples exhibited better induction-heating performance than hot mix asphalt mixture.

- The mean temperature of WMA mastic made with a virgin bituminous binder was higher than all other mastic types tested in this study. Modifying the binder with polymers (SBS, RWE, and RWP) degraded the heating capability, resulting in a lower average surface temperature and a weaker heat distribution uniformity.

- Evaluation of self-healing performances showed that, although specimens modified with SBS, RWE, and RWP had higher initial flexural strengths than those made with the virgin binder, they gave considerably smaller post-healing flexural strengths. In other words, the specimens made with the virgin asphalt binder had a greater self-healing rate and capacity compared with polymer-modified ones.

- Polymer modification of the bituminous binder increased the initial fracture energy of the mastic specimens, i.e., higher fracture energy was required for mechanical failure of the intact beams for the first time. The SBS-modified HMA and WMA mastic specimens gave the first and second highest initial values of fracture energy. However, the polymer modification appeared to somewhat undermine the post-healing fracture energy recovery, especially at shorter and earlier healing cycles. The fracture energy indices (HIs) of the virgin asphalt mastic specimens were considerably higher than the polymer-modified after the first three healing cycles with all cycle durations. At fourth and fifth cycles, the virgin-asphalt mastics still showed mostly higher HI values, but their difference was less significant than it was at the early cycles. At the fifth $80 \mathrm{~s}$ cycle, the SBS-modified specimens outperformed the virgin-asphalt specimens, exhibiting higher $\mathrm{HI}$.

Author Contributions: Conceptualization, M.F. and S.J.; methodology, M.F., S.J., R.S. and A.S.; investigation, S.J., R.S., A.S., A.A. and B.B.B.; writing—original draft preparation, S.J., R.S., A.S., A.A.; writing-review and editing, S.J., R.S., A.S. and A.A.; supervision, M.F. All authors have read and agreed to the published version of the manuscript.

Funding: This research received no external funding. 
Informed Consent Statement: This paper does not involve humans or animals.

Data Availability Statement: The authors of this paper will not report the data in the future.

Conflicts of Interest: The authors declare no conflict of interest.

\section{References}

1. Oreto, C.; Veropalumbo, R.; Viscione, N.; Biancardo, S.A.; Russo, F. Investigating the environmental impacts and engineering performance of road asphalt pavement mixtures made up of jet grouting waste and reclaimed asphalt pavement. Environ. Res. 2021, 198. [CrossRef]

2. Dondi, G.; Mazzotta, F.; Lantieri, C.; Cuppi, F.; Vignali, V.; Sangiovanni, C. Use of steel slag as an alternative to aggregate and filler in road pavements. Materials 2021, 14, 345. [CrossRef] [PubMed]

3. Ding, L.; Zhang, J.; Feng, B.; Li, C. Performance Evaluation of Recycled Asphalt Mixtures Containing Construction and Demolition Waste Applicated as Pavement Base. Adv. Civ. Eng. 2020, 2020. [CrossRef]

4. EAPA. The Asphalt Paving Industry. 2011, 2,36. Available online: http://www.asphaltpavement.org/images/stories/GL_101_ Edition_3.pdf (accessed on 15 August 2021).

5. Read, J.; Whiteoak, D. (Eds.) The Shell Bitumen Handbook; Thomas Telford Ltd.: London, UK, 2003; p. 29.

6. Grossegger, D.; Gomez-Meijide, B.; Vansteenkiste, S.; Garcia, A. Influence of rheological and physical bitumen properties on heat-induced self-healing of asphalt mastic beams. Constr. Build. Mater. 2018, 182, 298-308. [CrossRef]

7. Pan, P.; Wu, S.; Xiao, Y.; Liu, G. A review on hydronic asphalt pavement for energy harvesting and snow melting. Renew. Sustain. Energy Rev. 2015, 48, 624-634. [CrossRef]

8. Cui, P.Q.; Wu, S.P.; Xiao, Y.; Zhang, H.H. Experimental study on the reduction of fumes emissions in asphalt by different additives. Mater. Res. Innov. 2015, 19, S1158-S1161. [CrossRef]

9. Yanshan University. Design and Research of Parts and Walk Synchronization System of the Vehicle for Snow and Ice Removing Based on Mi-Crowave Heating; Yanshan University: Qinhuangdao, China, 2013.

10. García, A.; Bueno, M.; Norambuena-Contreras, J.; Partl, M.N. Induction healing of dense asphalt concrete. Constr. Build. Mater. 2013, 49, 1-7. [CrossRef]

11. Polacco, G.; Stastna, J.; Biondi, D.; Zanzotto, L. Relation between polymer architecture and nonlinear viscoelastic behavior of modified asphalts. Curr. Opin. Colloid Interface Sci. 2006, 11, 230-245. [CrossRef]

12. Airey, G.D. Styrene butadiene styrene polymer modification of road bitumens. J. Mater. Sci. 2004, 39, 3-4. [CrossRef]

13. Chen, J.-S.; Liao, M.-C.; Shiah, M.-S. Asphalt Modified by Styrene-Butadiene-Styrene Triblock Copolymer: Morphology and Model. J. Mater. Civ. Eng. 2002, 14, 224-229. [CrossRef]

14. Elseifi, M.A.; Flintsch, G.W.; Al-Qadi, I.L. Quantitative Effect of Elastomeric Modification on Binder Performance at Intermediate and High Temperatures. J. Mater. Civ. Eng. 2003, 15, 32-40. [CrossRef]

15. Nunn, M.E.; Smith, T. Road Trials of High Modulus Base for Heavily Trafficked Roads; TRL Project Report PR231; Thomas Telford Ltd.: London, UK, 1997.

16. Geng, H.; Clopotel, C.S.; Bahia, H.U. Effects of high modulus asphalt binders on performance of typical asphalt pavement structures. Constr. Build. Mater. 2013, 44, 207-213. [CrossRef]

17. Serfass, J.P.; Bense, P.; Pellevoisin, P.; Administration, F.H. Properties and new developments of high modulus asphalt concrete. In Proceedings of the Eighth International Conference on Asphalt Pavements, Seattle, Washington, USA, 10-14 August 1997; pp. 325-333.

18. Kumar, P.; Chandra, S.; Bose, S. R of the polymer modified Binders, Rheology of the polymer modified binders. 2004.

19. Lytton, R.L. Characterizing asphalt pavements for performance. Transp. Res. Rec. 2000, 5-18. [CrossRef]

20. Castro, M.; Sánchez, J.A. Fatigue and healing of asphalt mixtures: Discriminate analysis of fatigue curves. J. Transp. Eng. 2006, 132, 168-174. [CrossRef]

21. Phillips, M.C. Multi-step models for fatigue and healing, and binder properties involved in healing. Proc. Eurobitume Work. Perform. Relat. Prop. Bitum. Bind. 1998, 115.

22. Little, D.; Bhasin, A. Exploring mechanisms of healing in asphalt mixtures and quantifying its impact. In Self Healing Materials an Alternative approach to 20 Centuries of Materials Science; Springer: Dordrecht, The Netherlands, 2007; Volume 100, pp. 205-218.

23. Bhasin, A.; Bommavaram, R.; Vasconcelos, K.; Little, D.N. A framework to quantify the effect of healing in bituminous materials using material properties. Road Mater. Pavement Des. 2008, 9, 219-242. [CrossRef]

24. Kringos, N.; Schmets, A.; Pauli, T.; Scarpas, T. A finite element base chemo-mechanical model to similate healing in bitumen. In Proceedings of the International Workshop on Chemo-mechanics of Bituminous materials, Delft, The Netherlands, 9-11 June 2009.

25. García, Á. Self-healing of open cracks in asphalt mastic. Fuel 2012, 93, 264-272. [CrossRef]

26. Liu, Q.; Wu, S.; Schlangen, E. Induction heating of mastic asphalt for crack control. Constr. Build. Mater. 2013, 41, 345-351. [CrossRef]

27. Lesueur, D. The colloidal structure of bitumen: Consequences on the rheology and on the mechanisms of bitumen modification. Adv. Colloid Interface Sci. 2009, 145, 42-82. [CrossRef] [PubMed] 
28. Bhasin, A.; Palvadi, S.; Little, D.N. Influence of aging and temperature on intrinsic healing of asphalt binders. Transp. Res. Rec. 2011, 70-78. [CrossRef]

29. Lv, Q.; Huang, W.; Zhu, X.; Xiao, F. On the investigation of self-healing behavior of bitumen and its influencing factors. Mater. Des. 2017, 117, 7-17. [CrossRef]

30. Sun, D.; Lin, T.; Zhu, X.; Tian, Y.; Liu, F. Indices for self-healing performance assessments based on molecular dynamics simulation of asphalt binders. Comput. Mater. Sci. 2016, 114, 86-93. [CrossRef]

31. Qiu, J.; van de Ven, M.; Wu, S.; Yu, J.; Molenaar, A. Evaluating Self Healing Capability of Bituminous Mastics. Exp. Mech. 2012, 52, 1163-1171. [CrossRef]

32. Qiu, J.; Van de Ven, M.; Wu, S.; Molenaar, A.; Yu, J. Self-healing characteristics of bituminous mastics using a modified direct tension test. J. Intell. Mater. Syst. Struct. 2014, 25, 58-66. [CrossRef]

33. Removal, S. Ice Control Research, Special Report 115; Highway Research Board and US Army Cold Regions Research and Engineering Laboratory: Washington, DC, USA, 1970.

34. Osborne, T.; Hutcheson, W. Asphalt Compounds and Method for Asphalt Reconditioning Using Microwave Radiation. U.S. Patent 4,849,020, 18 July 1989.

35. Zhang, Q.; Yu, Y.; Chen, W.; Chen, T.; Zhou, Y.; Li, H. Outdoor experiment of flexible sandwiched graphite-PET sheets based self-snow-thawing pavement. Cold Reg. Sci. Technol. 2016, 122, 10-17. [CrossRef]

36. Zhou, Z.; Wang, X.; Zhang, X.; Chen, G.; Zuo, J.; Pullen, S. Effectiveness of pavement-solar energy system-An experimental study. Appl. Energy 2015, 138, 1-10. [CrossRef]

37. Sun, Y.; Wu, S.; Liu, Q.; Hu, J.; Yuan, Y.; Ye, Q. Snow and ice melting properties of self-healing asphalt mixtures with induction heating and microwave heating. Appl. Therm. Eng. 2018, 129, 871-883. [CrossRef]

38. Liu, Q.; Yu, W.; Wu, S.; Schlangen, E.; Pan, P. A comparative study of the induction healing behaviors of hot and warm mix asphalt. Constr. Build. Mater. 2017, 144, 663-670. [CrossRef]

39. Fakhri, M.; Bahmai, B.B.; Javadi, S.; Sharafi, M. An evaluation of the mechanical and self-healing properties of warm mix asphalt containing scrap metal additives. J. Clean. Prod. 2020, 253. [CrossRef]

40. Xu, S.; García, A.; Su, J.; Liu, Q.; Tabaković, A.; Schlangen, E. Self-Healing Asphalt Review: From Idea to Practice. Adv. Mater. Interfaces 2018, 5. [CrossRef]

41. Liu, X.; Zhang, M.; Shao, L.; Chen, Z. Effect of volcanic ash filler on thermal viscoelastic property of SBS modified asphalt mastic. Constr. Build. Mater. 2018, 190, 495-507. [CrossRef]

42. Arabzadeh, A.; Guler, M. Thermal fatigue behavior of asphalt concrete: A laboratory-based investigation approach. Int. J. Fatigue 2019, 121, 229-236. [CrossRef]

43. Fakhri, M.; Haghighat Kharrazi, E.; Aliha, M.R.M. Mixed mode tensile-In plane shear fracture energy determination for hot mix asphalt mixtures under intermediate temperature conditions. Eng. Fract. Mech. 2018, 192, 98-113. [CrossRef]

44. Salih, S.; Gómez-Meijide, B.; Aboufoul, M.; Garcia, A. Effect of porosity on infrared healing of fatigue damage in asphalt. Constr Build. Mater. 2018, 167, 716-725. [CrossRef]

45. Sun, J.; Wang, W.; Yue, Q. Review on microwave-matter interaction fundamentals and efficient microwave-associated heating strategies. Materials 2016, 9, 231. [CrossRef] [PubMed]

46. Bait-Suwailam, M.M. Electromagnetic Field Interaction with Metamaterials. Electromagn. Fields Waves 2019. [CrossRef]

47. Al-Ohaly, A.A. Laboratory Evaluation of Microwave Heated Asphalt Pavement Materials. Ph.D. Thesis, University of Washington, Seattle, WA, USA, 1987.

48. Vlachovicova, Z.; Stastna, J.; Zanzotto, L. Shear Viscosity and Dielectric Permittivity in Asphalt Modified By SBS. Pet. Coal 2003, 45, 178-183.

49. Chen, F.; Taylor, N.; Kringos, N.; Birgisson, B. A study on dielectric response of bitumen in the low-frequency range. Road Mater. Pavement Des. 2015, 16, 153-169. [CrossRef]

50. Sassani, A.; Arabzadeh, A.; Ceylan, H.; Kim, S.; Gopalakrishnan, K.; Taylor, P.C.; Nahvi, A. Polyurethane-carbon microfiber composite coating for electrical heating of concrete pavement surfaces. Heliyon 2019, 5. [CrossRef]

51. Arabzadeh, A.; Notani, M.A.; Kazemiyan Zadeh, A.; Nahvi, A.; Sassani, A.; Ceylan, H. Electrically conductive asphalt concrete: An alternative for automating the winter maintenance operations of transportation infrastructure. Compos. Part B Eng. 2019, 173. [CrossRef]

52. Arabzadeh, A.; Ceylan, H.; Kim, S.; Gopalakrishnan, K.; Sassani, A. Superhydrophobic coatings on asphalt concrete surfaces: Toward smart solutions for winter pavement maintenance. Transp. Res. Rec. 2016, 2551, 10-17. [CrossRef]

53. Benedetto, A.; Calvi, A. A pilot study on microwave heating for production and recycling of road pavement materials. Constr. Build. Mater. 2013, 44, 351-359. [CrossRef]

54. Bennert, T.; Reinke, G.; Mogawer, W.; Mooney, K. Assessment of workability and compactability of warm-mix asphalt. Transp. Res. Rec. 2010, 36-47. [CrossRef]

55. Behnood, A. A review of the warm mix asphalt (WMA) technologies: Effects on thermo-mechanical and rheological properties. J. Clean. Prod. 2020, 259. [CrossRef]

56. Jamshidi, A.; Hamzah, M.O.; You, Z. Performance of Warm Mix Asphalt containing Sasobit@: State-of-the-art. Constr. Build. Mater. 2013, 38, 530-553. [CrossRef] 
57. Sassani, A.; Ceylan, H.; Kim, S.; Arabzadeh, A.; Taylor, P.C.; Gopalakrishnan, K. Development of Carbon Fiber-modified Electrically Conductive Concrete for Implementation in Des Moines International Airport. Case Stud. Constr. Mater. 2018, 8, 277-291. [CrossRef]

58. Liu, K.; Xu, P.; Wang, F.; Jin, C.; Huang, M.; Dai, D.; Fu, C. Deicing efficiency analysis and economic-environment assessment of a novel induction heating asphalt pavement. J. Clean. Prod. 2020, 273. [CrossRef]

59. Zohuri, B. Chapter 6-second law of thermodynamics. Phys. Cryogen 2018, 165-183.

60. Mishra, R.R.; Sharma, A.K. Microwave-material interaction phenomena: Heating mechanisms, challenges and opportunities in material processing. Compos. Part A Appl. Sci. Manuf. 2016, 81, 78-97. [CrossRef]

61. Barri, K.; Jahangiri, B.; Davami, O.; Buttlar, W.G.; Alavi, A.H. Smartphone-based molecular sensing for advanced characterization of asphalt concrete materials. Measurement 2020, 151, 107212. [CrossRef]

62. Galindo, B.; Benedito, A.; Ramos, F.; Gimenez, E. Microwave heating of polymers: Influence of carbon nanotubes dispersion on the microwave susceptor effectiveness. Polym. Eng. Sci. 2016, 56, 1321-1329. [CrossRef]

63. Dai, Q.; Wang, Z.; Mohd Hasan, M.R. Investigation of induction healing effects on electrically conductive asphalt mastic and asphalt concrete beams through fracture-healing tests. Constr. Build. Mater. 2013, 49, 729-737. [CrossRef]

64. Pirmohammad, S.; Ayatollahi, M.R. Fracture Behavior of Asphalt Materials; Springer Nature: Basingstoke, UK, 2020; pp. 157-180.

65. Bazzaz, M.; Darabi, M.K.; Little, D.N.; Garg, N. A straightforward procedure to characterize nonlinear viscoelastic response of asphalt concrete at high temperatures. Transp. Res. Rec. 2018, 2672, 481-492. [CrossRef]

66. Darabi, M.K.; Huang, C.W.; Bazzaz, M.; Masad, E.A.; Little, D.N. Characterization and validation of the nonlinear viscoelasticviscoplastic with hardening-relaxation constitutive relationship for asphalt mixtures. Constr. Build. Mater. 2019, 216, 648-660. [CrossRef]

67. Bazzaz, M.; Darabi, M.K.; Little, D.N.; Garg, N. Effect of evotherm-M1 on properties of asphaltic materials used at NAPMRC testing facility. J. Test. Eval. 2019, 48. [CrossRef] 